\title{
Intoxicação natural por Amaranthus spinosus (Amaranthaceae) em ovinos no Sudeste do Brasil ${ }^{1}$
}

\author{
Paulo Vargas Peixoto ${ }^{2}$, Luis Armando Calvão Brust ${ }^{3}$, Marilene de Farias Brito ${ }^{4}$, \\ Ticiana do Nascimento França ${ }^{5}$, Bernardo Rosa Melo da Cunha ${ }^{3}$ e Gisele Braziliano \\ de Andrade ${ }^{4}$
}

\begin{abstract}
Peixoto P.V., Brust L.A.C., Brito M.F., França T.N., Cunha B.R.M. \& Andrade G.B. 2003. [Amaranthus spinosus (Amaranthaceae) poisoning in sheep in southern Brazil.] Intoxicação natural por Amaranthus spinosus (Amaranthaceae) em ovinos no Sudeste do Brasil. Pesquisa Veterinária Brasileira 23(4):179-184. Depto Nutrição Animal e Pastagem, Inst Zootecnia, UFRRJ, Seropédica, RJ 23835-000, Brazil.

An outbreak of acute poisoning caused by Amaranthus spinosus is described in ewes of southern Brazil. The clinical signs were characterized by uremic halitosis, loss of ruminal motility, dispnoea and abortion. Grossly in the kidneys there were pale red spots, white streaks extending from cortex to medulla, and congestion. Histologically there was a severe acute tubular nephrosis, dispersed foci of coagulative necrosis in the liver, areas of coagulative necrosis in the myocardium and acute incipient interstitial pneumonia as well as secondary bronchopneumonia. Myocardial coagulative necrosis observed in seven sheep was attributed to hyperkalemia secondary to renal insufficiency. No references to spontaneous $A$. spinosus poisoning in sheep was found in the literature. Attempt to reproduce the poisoning by administration of the plant to sheep was insuccessful, probably because $A$. spinosus used was not from fertilized areas.
\end{abstract}

INDEX TERMS: Poisonous plants, plant poisononig, Amaranthus spinosus, Amaranthaceae, sheep, pathology.

RESUMO.- No Estado do Rio de Janeiro descreve-se um surto de intoxicação aguda por Amaranthus spinosus em 12 ovelhas, caracterizado clinicamente por hálito urêmico, ausência de movimentos ruminais, dispnéia e aborto. Os animais foram colocados em um pasto adubado e severamente invadido pela planta. A necropsia realizada em seis ovinos revelou rins pálidos, em geral, com estriações esbranquiçadas desde o córtex até a medula; em um animal verificaram-se diversos infartos sob forma de figuras geométricas no córtex. $\mathrm{O}$ figado apresentava-se mais claro, por vezes com lobulação evidente. Em um animal verificaram-se áreas pálidas no miocárdio. Os pulmões congestos, algo

${ }^{1}$ Recebido em 15 de agosto de 2003.

Aceito para publicação em 23 de setembro de 2003.

${ }^{2}$ Depto Nutrição Animal e Pastagem, Instituto de Zootecnia, Universidade Federal Rural do Rio de Janeiro (UFRRJ), Seropédica, RJ 23835-000. *Autor para correspondência. E-mail: peixotop@ufrrj.br

${ }^{3}$ Mestrando do Curso de Medicina Veterinária da UFRRJ.

${ }^{4}$ Disciplina de Anatomia Patológica, Depto Epidemiologia e Saúde Pública, Instituto de Veterinária, UFRRJ.

${ }^{5}$ Disciplina de Anatomia Patológica, Curso de Medicina Veterinária, Universidade Estácio de Sá, Estrada da Boca do Mato 850, Vargem Pequena, RJ 22783-320. E-mail: ticianaf@uol.com.br mais pesados e consistentes, por vezes evidenciavam áreas de hepatização vermelha e cinzenta na porção cranial. Petéquias, equimoses e sufusões foram observadas em serosas, na mucosa do tubo digestório e em outros órgãos. Ao exame histológico verificaram-se acentuada nefrose tubular tóxica, focos aleatórios de necrose coagulativa no figado, áreas de necrose coagulativa no miocárdio e pneumonia intersticial aguda incipiente acompanhada por áreas de broncopneumonia. Na literatura não foram encontradas referências à intoxicação natural por $A$. spinosus em ovinos. Tentativas de reprodução da intoxicação com a planta em ovinos, não foram bem sucedidas, provavelmente porque, nos experimentos, não se utilizou $A$. spinosus proveniente de áreas adubadas. A necrose do miocárdio encontrada, ao exame microscópico do coração de diversos animais foi atribuída a hipercalemia secundária à insuficiência renal, ao passo que a gênese dos infartos renais verificados em um ovino permanece obscura.

TERMOS DE INDEXAÇÃO: Plantas tóxicas, intoxicação por plantas, Amaranthus spinosus, Amaranthaceae, ovino, patologia.

\section{INTRODUÇÃO}

A ingestão de plantas do gênero Amaranthus pode causar dois tipos básicos de intoxicação. $O$ primeiro tipo é caracterizado 
por nefrose tubular tóxica, que, em geral, cursa com edemas, sobretudo perirrenal, por vezes associado à presença de cristais de oxalatos nos túbulos uriníferos; a evolução desse quadro é de alguns dias. O segundo tipo manifesta-se com metemoglobinemia decorrente dos altos níveis de nitratos/ nitritos presentes na planta, com evolução de poucas horas (Tokarnia et al. 2000).

Em bovinos, a nefrose tubular tóxica tem sido associada à ingestão de Amaranthus hybridus, A. blitum, A. spinosus, A. quitensis e de $A$. retroflexus, e nos suínos à ingestão de $A$. caudatus, A. viridis, A. quitensis e A. retroflexus (Jeppesen 1966, Cursack \& Romano 1967, Stuart et al. 1975, Duffy et al. 1985, Armesto et al. 1989, Ferreirra et al. 1991, Lemos et al. 1993, Larsen 1962, Buck 1965, 1966, Osweiller 1969, Sanko 1975, Cho \& Lee 1984, Takken 1985, Salles et al. 1991, Kommers 1996). No Brasil, foi relatada a intoxicação natural em bovinos, determinada pela ingestão de $A$. hybridus, $A$. blitum (Ferreira et al. 1991) e A. spinosus (Lemos et al. 1993), e em suínos ligada à ingestão de $A$. viridis e $A$. quitensis (Salles et al. 1991), sempre cursando com nefrose tubular tóxica.

A nefrose por oxalatos em caprinos e ovinos é citada por González (1983).

O quadro de metemoglobinemia causada pelo excesso de nitritos é descrito em bovinos que ingeriram $A$. hybridus, $A$. viridis, $A$. retroflexus e, em caprinos e em ovinos, pela ingestão de $A$. retroflexus (Brackenridge 1956, Dodd \& Coup 1957, Egyed \& Miller 1963, Cursack \& Romano 1967, Strom 1967, Duckworth 1975, Rivera et al. 1984).

Aparentemente há alguns equívocos na literatura em relação a esses diferentes quadros clínico-patológicos; Cursak \& Romano (1967) relatam a ocorrência de um surto em bovinos com sintomatologia e achados de necropsia característicos de nefrose tubular tóxica como uma possível intoxicação subaguda por nitratos e nitritos.

Também já foram descritas, em ovelhas, a intoxicação natural por "pigweed” (A. retroflexus) (Strom 1967, González 1983) e a tentativa de reprodução experimental (Mugerwa 1967), sendo que Strom (1967) refere-se a um quadro de metemoglobinemia causado por nitritos e nitratos e González (1983) relata nefrose por cristais de oxalatos. Mais recentemente há descrição de intoxicação em ovinos recém-desmamados que foram colocados em pastagem intensamente invadida por $A$. retroflexus, o qual foi consumido em grande quantidade durante os 10 dias de permanência nesse pasto (Rae \& Binnington 1995).

O objetivo deste trabalho é descrever um surto espontâneo de intoxicação por $A$. spinosus em ovinos, no Sudeste do Brasil, caracterizado por nefrose tubular.

\section{MATERIAL E MÉTODOS}

Foi investigada uma mortandade no município de Paraíba do Sul, Estado do Rio de Janeiro, na qual 12 ovelhas morreram; seis desses ovinos foram necropsiados nas dependências do Setor de Anatomia Patológica, Projeto Sanidade Animal Embrapa/UFRRJ, e dois outros foram necropsiados pelo Veterinário da propriedade. Fragmentos de rim, fígado, baço, coração, pulmão, linfonodos, adrenal, sistema nervoso central e sistema digestório foram colhidos e fixados em formol a $10 \%$. O material coletado para exame histopatológico foi processado pelos métodos rotineiros, inclúído em parafina, cortado na espessura de $5 \mu$ e corado pela hematoxilina-eosina (HE). Um fragmento de rim de feto foi corado pela hematoxilina fosfotúngstica de Mallory.

Na tentativa de reprodução do quadro de intoxicação duas ovelhas, mestiças, adultas, foram alimentados exclusivamente $\operatorname{com} A$. spinosus (Fig. 1); Ovino 1, durante 36 dias e Ovino 2, durante 32 dias.

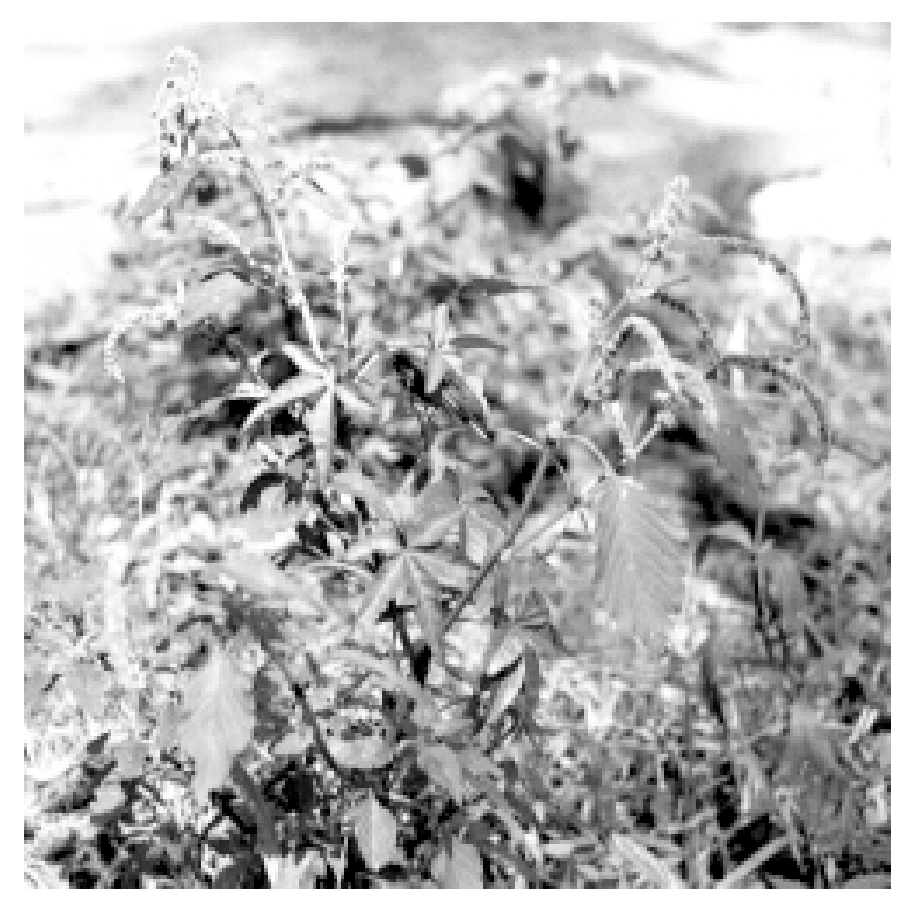

Fig. 1. Amaranthus spinosus (fam. Amaranthaceae) em frutificação.

\section{RESULTADOS}

Histórico

Em junho de 1997 verificou-se uma enfermidade em ovinos, no município de Paraíba do Sul, Estado do Rio de Janeiro. Cinqüenta ovelhas prenhes (no último mês de gestação), de um total de 200 , foram colocados em uma área de 2 hectares, cercada, onde anteriormente era um pasto de "coast cross" que tinha sido adubado com rocha fosfática $(400 \mathrm{~kg} / \mathrm{ha})$ em torno de 5 a 6 meses antes da ocorrência do surto. Esse piquete estava invadido por grande quantidade de Amaranthus spinosus, vulgarmente chamada de caruru que era praticamente a única fonte de alimento para esses animais. Um dia após a entrada nesse local, os animais foram retirados para que a "pastagem" fosse roçada, só retornando ao piquete na manhã do dia seguinte; porém, continuaram a ingerir tanto o Amaranthus fresco quanto a palhada, após a roçagem. Cinco dias após retornarem ao piquete, 12 ovelhas adoeceram; durante esse período, nenhum animal abortou. Após o início dos sintomas, todos os animais foram retirados desse local. Doze ovelhas adoeceram entre 11 e 14 de junho de 1997 e oito desses animais morreram; dos seis animais por nós necrospsiados, dois morreram durante a viagem, dois foram sacrificados "in extremis" e dois outros morreram naturalmente no dia seguinte. 


\section{Sintomatologia}

Na propriedade, 12 ovelhas apresentaram dispnéia, hálito urêmico e decúbito. As ovelhas enfermas morreram no período de uma semana com uma evolução de 2 a 4 dias. 0 exame clínico foi realizado em dois animais que chegaram doentes. Os animais estavam em bom estado nutricional, evidenciaram hálito urêmico, ausência de movimentos ruminais, dispnéia e espuma esbranquiçada pelas narinas. À auscultação verificaram-se som de líquido na laringe durante a respiração e estertores pulmonares à inspiração. Segundo o proprietário, regurgitaram durante a viagem. As mucosas oral, ocular e vaginal estavam congestas e os vasos episclerais ingurgitados. Na fase final verificou-se diminuição ou ausência dos reflexos pupilar, palpebral, auricular e anal e menor sensibilidade nos membros de um dos animais. Os animais examinados foram encontrados mortos na manhã do dia seguinte.

\section{Achados de necropsias}

Os rins encontravam-se mais pálidos (6/6), com pontos avermelhados na superfície (1/6) e estriações esbranquiçadas que iam desde o córtex até a região medular (4/6); havia congestão da medula (1/6) e diversos infartos hemorrágicos, sob forma de figuras geométricas no córtex renal (1/6). As principais alterações observadas no tubo digestivo foram averme-lhamento (1/ 6) e ulcerações na mucosa do abomaso (2/6), avermelhamento da mucosa do intestino delgado (3/6) e presença de conteúdo marrom-avermelhado ou hemorrágico (2/6). 0 figado apresentava-se mais claro (6/6), com lobulação evidente (5/6) e com áreas esbranquiçadas, medindo aproximadamente $1 \mathrm{~cm}$ de diâmetro, distribuídas pelo parênquima (1/6).

Na superfície de corte do miocárdio observaram-se pequenas, porém nítidas, áreas esbranquiçadas (1/6). Hemorragias sob forma de petéquias na traquéia $(1 / 6)$, sulco coronário $(1 / 6)$, tecido subcutâneo da região torácica $(1 / 6)$, pulmão e pleura parietal $(1 / 6)$ e de sufusões na parede do ceco e na serosa do jejuno; adicionalmente verificou-se um grande coágulo no mesentério da região duodenal (1/6).

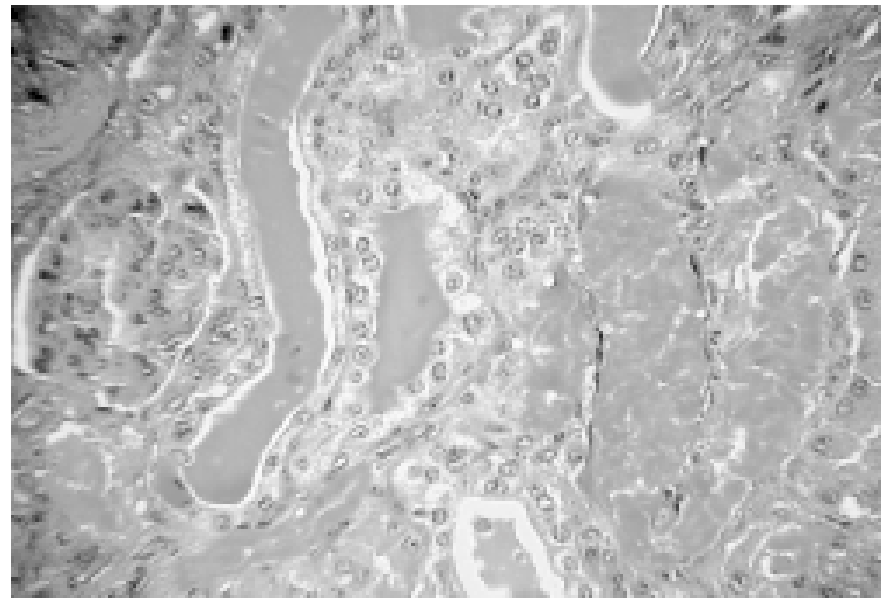

Fig. 2. Intoxicação natural por Amaranthus spinosus em ovinos. Necrose coagulativa de células epiteliais dos túbulos uriníferos (pontas de setas) e cilindros hialinos (setas). HE, obj. 25.
No pulmão foram observados congestão (4/6), áreas avermelhadas ligeiramente deprimidas na superfície dorsal do lobo cardíaco, com presença de dois focos esbranquiçados de aproximadamente $1,5 \mathrm{~cm}$ de diâmetro (1/6), áreas crânioventrais de dois lobos pulmonares algo mais pesadas e consistentes, com presença de fibrina (1/6), aparência vítrea na superfície pulmonar (1/6) e lobo crânio-ventral mais consistente (1/6). Nos animais necropsiados havia, no útero, feto em avançado estado autolítico (1/6) e em outro se observou um feto no canal vaginal $(1 / 6)$.

\section{Alterações histopatológicas}

A principal alteração microscópica caracterizou-se por nefrose tubular aguda, com necrose de coagulação (Fig. 2, 3, 5), "degeneração em gotas hialinas" das células epiteliais dos túbulos contornados (Fig. 4) e presença de cilindros eosinofilicos na luz de vários túbulos (Fig. 2). Ainda foram encontradas importantes alterações no coração, sob forma de focos ou áreas relativamente extensas de necrose coagulativa (7/8), por vezes acompanhadas de discreta reação inflamatória mista incipiente (2/8). No figado havia microfocos de necrose coagulativa, distribuídos aleatoriamente (6/8). No pulmão, as principais alterações foram pneumonia intersticial incipiente (3/8) e áreas de broncopneumonia exsudativa secundária (7/8). As lesões renais e extra-renais mais importantes encontram-se detalhadas nos Quadros 1 e 2.

\section{Casos experimentais}

Os dois ovinos submetidos à experimentação com Amaranthus spinosus, não demonstraram sintomas de intoxicação. A ingestão total da planta foi de $131,8 \mathrm{~g} / \mathrm{kg}$ para Ovino 1 e $206,7 \mathrm{~g} / \mathrm{kg}$ para Ovino 2.

\section{DISCUSSÃO}

A intoxicação por Amaranthus spinosus ainda não havia sido relatada em ovinos. O diagnóstico da intoxicação por essa planta baseou-se nos dados epidemiológicos, nos sinais clínicos, nos

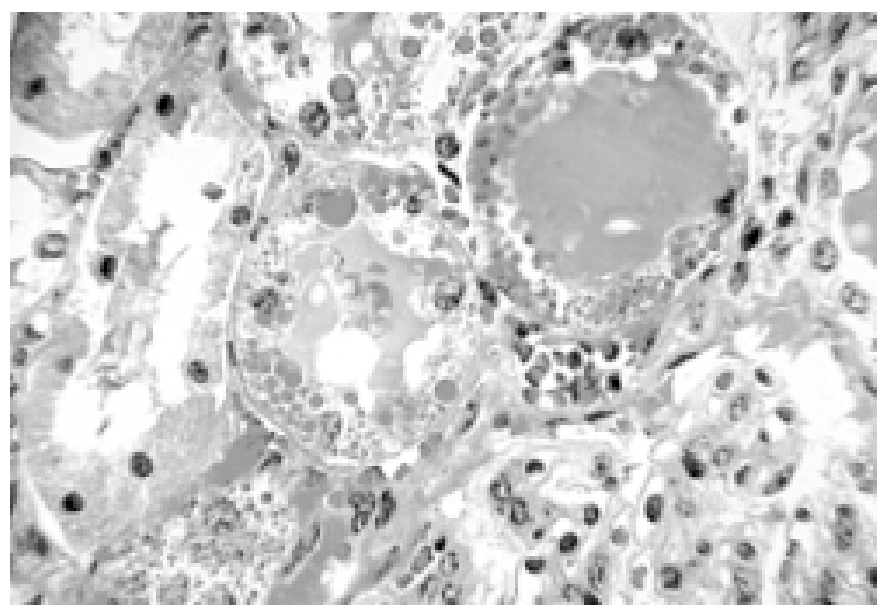

Fig. 3. "Degeneração em gotas hialinas" nas células epiteliais dos túbulos uriníferos, na intoxicação natural por $A$. spinosus em ovino. HE, obj. 40. 


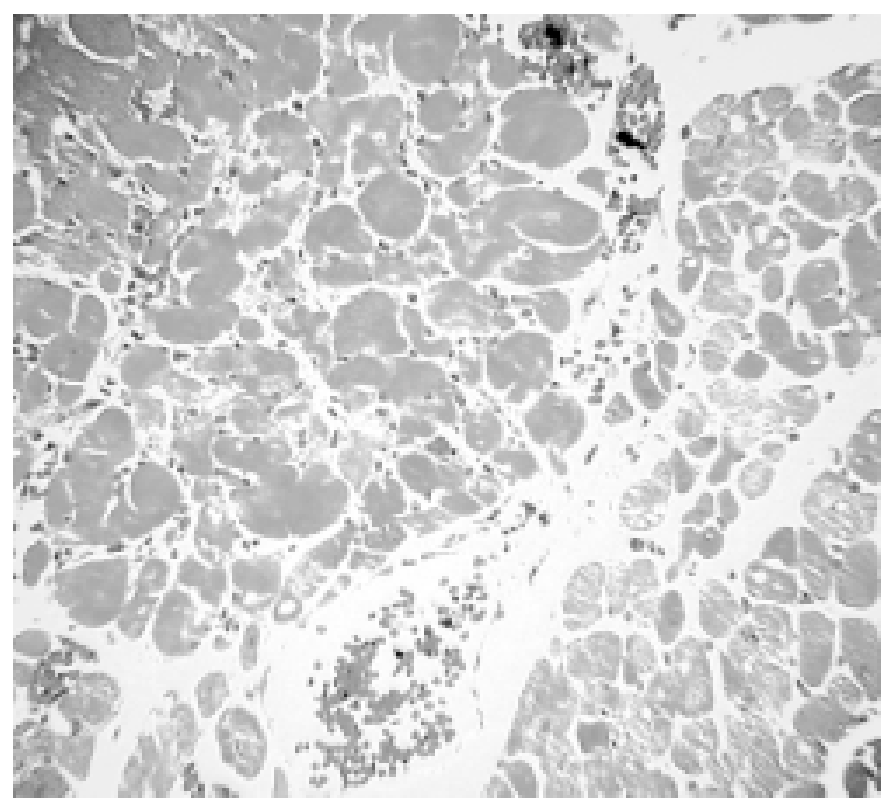

Fig. 4. Focos de necrose coagulativa no miocárdio, na intoxicação natural por Amarnthus spinosus em ovino. HE, obj. 10.

achados de necropsia e em exames histopatológicos que se assemelhavam ao que é descrito para a forma nefrotóxica da intoxicação por plantas do gênero Amaranthus (Jeppesen 1966, Cursack \& Romano 1967, Stuart et al. 1975, Duffy et al. 1985, Armesto et al. 1989, Ferreira et al. 1991). Além do fato de $A$. spinosus ser a única forragem verde disponível no piquete (e de ter sido ingerida em grande quantidade), o exame minucioso do terrreno não revelou quaisquer outros agentes nefrotóxicos. Esses achados confirmam o diagnóstico da toxicose.

Na literatura há alguns equívocos e incongruências com relação aos diferentes quadros clínico-patológicos provocados por plantas do gênero Amaranthus. Cursack (1967) atribui a ocorrência de um surto em bovinos a toxicose subaguda por nitratos/nitritos, contidos em $A$. hybridus var. quitensis, entretanto as lesões descritas no trabalho são características de nefrose tubular tóxica. Sabe-se que inúmeras plantas são capazes de, sob variadas condições, armazenar quantidades tóxicas de nitratos (Clarke et al. 1981) e provocar metemoglobinemia; no entanto, nenhum ovino deste estudo demonstrou quadro clínico ou lesões semelhantes aos desenvolvidos na intoxicação por nitratos/nitritos. Por outro lado, neste trabalho, não se verificou a presença de cristais de oxalatos associados à lesão renal, como descrito por Marshal et al. (1967) e González (1983).

A época do ano em que ocorreu o surto aqui descrito e o estágio vegetativo de frutificação em que se encontrava a planta tóxica, coincidem com os dos surtos descritos nos EUA (Jeppesen 1966), na Argentina (Duffy et al. 1985) e no Brasil (Ferreira et al. 1991).

Outras plantas nefrotóxicas que existem no Brasil, como Thiloa glaucocarpa, Dimorphandra mollis e D. gardneriana, podem causar quadro clínico-patológico bastante semelhante ao provocado por Amaranthus spp, entretanto T. glaucocarpa e D. gardneriana não ocorrem no Estado do Rio de Janeiro e

Quadro 1. Principais alterações histológicas renais na intoxicação natural por Amaranthus spinosus em ovinos

\begin{tabular}{|c|c|c|c|c|c|c|c|c|}
\hline Alteração & $\begin{array}{c}\text { Ovino } 1 \\
28366-A \\
\end{array}$ & $\begin{array}{c}\text { Ovino } 2 \\
28360\end{array}$ & $\begin{array}{c}\text { Ovino } 3 \\
28365\end{array}$ & $\begin{array}{c}\text { Ovino } 4 \\
28359\end{array}$ & $\begin{array}{c}\text { Ovino } 5 \\
28510\end{array}$ & $\begin{array}{c}\text { Ovino } 6 \\
28513 \\
\end{array}$ & $\begin{array}{c}\text { Ovino } 7 \\
28358 \\
\end{array}$ & $\begin{array}{c}\text { Ovino } 8 \\
28356 \\
\end{array}$ \\
\hline \multicolumn{9}{|l|}{ Glomérulos } \\
\hline Tumefação das células da cápsula de Bowman & $(+)$ & + & + & + & + & + & - & $(+)$ \\
\hline Aumento do filtrado glomerular & - & $(+)$ & $(+)$ & + & + & + & $(+)$ & $(+)$ \\
\hline Congestão glomerular & - & - & - & - & +++ & - & - & ++ \\
\hline Congestão do córtex & ++ & - & $+(+)$ & $(+)$ & +++ & - & - & ++ \\
\hline Microtrombos hialinos & - & - & - & + & - & - & - & - \\
\hline Microtrombos fibrinosos & - & - & $(+)$ & + & $++(+)$ & - & - & - \\
\hline \multicolumn{9}{|l|}{ Túbulos } \\
\hline Tumefação de células epiteliais & + & - & $+\mathrm{l}^{\mathrm{*}}$ & - & + & +1 & & - \\
\hline Degeneração "em gotas hialinas" & $(+)^{1}$ & - & + & - & - & +1 & & + \\
\hline Vacuolização de células epiteliais & $(+)$ & - & - & +1 & $(+)$ & + & & - \\
\hline Necrose coagulativa & $++(+)$ & +++ & +++ & ++ & +++ & $+/+++$ & + & +++ \\
\hline Calcificação & - & - & - & - & ++ & - & $+\mathrm{p}$ & - \\
\hline Proteína na luz tubular & $+/++$ & $(+)$ & ++ & ++ & +++ & $+/++$ & ++ & $+++^{\mathrm{e}}$ \\
\hline Cilindros hialinos & $++(+)$ & & + & - & $+(+)$ & ++ & ++ & + \\
\hline Dilatação tubular & $+(+)$ & - & - & + & + & - & ++ & - \\
\hline Hemorragia & - & - & - & $(+)$ & ++ & - & - & + \\
\hline \multicolumn{9}{|l|}{ Interstício } \\
\hline Edema intersticial & - & $(+)$ & - & $(+)$ & + & + & & - \\
\hline Congestão & + & $++^{m}$ & $++^{\mathrm{m}}$ & + & ++ & $++^{\mathrm{m}}$ & & $++^{\mathrm{m}}$ \\
\hline Infiltrado polimorfonuclear & - & $(+)$ & - & + & $++^{\mathrm{t}}$ & $(+)$ & & $++^{\mathrm{t}}$ \\
\hline Infiltrado mononuclear & + & - & $(+)$ & $(+)$ & + & + & & - \\
\hline Hemorragia & + & - & + & - & + & - & & + \\
\hline
\end{tabular}

${ }^{*} \mathrm{l}=$ com evolução para lise, $\mathrm{e}=$ com infiltrado neutrofilico em meio ao material proteináceo, $\mathrm{p}=$ pelve, $\mathrm{m}=\mathrm{medular}, \mathrm{t}=$ infiltrado no interior dos túbulos. 
Quadro 2. Principais alterações histológicas extra-renais na intoxicação natural por Amaranthus spinosus em ovinos

\begin{tabular}{|c|c|c|c|c|c|c|c|c|}
\hline Órgão & $\begin{array}{c}\text { Ovino } 1 \\
\text { 28366-A }\end{array}$ & $\begin{array}{c}\text { Ovino } 2 \\
28360\end{array}$ & $\begin{array}{c}\text { Ovino } 3 \\
28365\end{array}$ & $\begin{array}{c}\text { Ovino } 4 \\
28359\end{array}$ & $\begin{array}{c}\text { Ovino } 5 \\
28510\end{array}$ & $\begin{array}{c}\text { Ovino } 6 \\
28513\end{array}$ & $\begin{array}{c}\text { Ovino } 7 \\
28358\end{array}$ & $\begin{array}{c}\text { Ovino } 8 \\
28356\end{array}$ \\
\hline \multicolumn{9}{|l|}{ Coração } \\
\hline $\begin{array}{l}\text { Necrose de coagulação } \\
\text { Infiltrado inflamatório misto } \\
\text { Vacuolização }\end{array}$ & s/a & $(+)^{\mathrm{a}^{3}}$ & ++ & $\begin{array}{c}++(+)^{i} \\
(+)\end{array}$ & $\begin{array}{c}+(+) \\
(+)\end{array}$ & $\begin{array}{l}++^{\mathrm{f}} \\
++\end{array}$ & $(+)$ & + \\
\hline \multicolumn{9}{|l|}{ Pulmão } \\
\hline $\begin{array}{l}\text { Congestão } \\
\text { Hemorragias }\end{array}$ & ++ & $\begin{array}{l}+++ \\
+++\end{array}$ & + & + & $++(+)$ & ++ & $+(+)$ & $++(+)$ \\
\hline $\begin{array}{l}\text { Edema alveolar } \\
\text { Pneumonia intersticial aguda }\end{array}$ & + & & + & & $+{ }^{\mathrm{di}}$ & ++ & $+(+)^{\mathrm{i}}$ & $\begin{array}{c}++(+) \\
++^{i}\end{array}$ \\
\hline $\begin{array}{l}\text { Broncopneumonia necrotizante } \\
\text { Broncopneumonia exsudativa } \\
\text { Bronquite e bronquiolite }\end{array}$ & & $+++^{c}$ & $++^{c}$ & + & $++^{c}$ & $?$ & + & ++ \\
\hline \multicolumn{9}{|l|}{ Abomaso } \\
\hline $\begin{array}{l}\text { Congestão } \\
\text { Hemorragia } \\
\text { Edema da submucosa } \\
\text { Ulceração } \\
\text { Trombos hialinos }\end{array}$ & & $\mathrm{s} / \mathrm{a}$ & & $\mathbf{s} / \mathbf{a}$ & $\begin{array}{l}+ \\
+ \\
+(+) \\
+ \\
+\end{array}$ & + & $n / c$ & $\begin{array}{l}+ \\
+\end{array}$ \\
\hline $\begin{array}{l}\text { Fígado } \\
\text { Congestão } \\
\text { Vacuolização } \\
\text { Necrose coagulativa } \\
\text { Trombos hialinos } \\
\text { Citossegressomos } \\
\text { Corpúsculos de choque }\end{array}$ & $\begin{array}{l}(+)^{\mathrm{pa}} \\
(+)^{\mathrm{pa}}\end{array}$ & $+^{d}$ & $\begin{array}{l}(+)^{\mathrm{f}} \\
(+)\end{array}$ & $\mathbf{s} / \mathbf{a}$ & $(+)^{\mathrm{pa}}$ & $\begin{array}{c}+ \\
(+)^{\text {pa }}\end{array}$ & $\begin{array}{c}+\mathrm{zi} \\
(+)^{\mathrm{a}}\end{array}$ & $+^{f}$ \\
\hline
\end{tabular}

${ }^{*} \mathrm{~s} / \mathrm{a}=$ sem alterações, $\mathrm{a}=$ aleatória, $\mathrm{i}=$ incipiente, $\mathrm{f}=$ focal, $\mathrm{c}=$ com numerosas colônias bacterianas, di $=$ difusa incipiente, $\mathrm{i}=$ incipiente, $\mathrm{zi}=$ zona intermediária, $\mathrm{n} / \mathrm{c}=$ não coletado, $\mathrm{di}=$ difusa incipiente, $\mathrm{pa}=$ paracentral, $\mathrm{zi}=$ zona intermediária.

D. mollis não foi observada na região em questão. Considerando-se que os casos de intoxicação por $A$. spinosus sejam escassos e que a planta tenha boa palatabilidade, já que alguns animais a ingerem como forrageira, acreditamos que certos fatores envolvidos na epidemiologia da intoxicação não estão bem esclarecidos. Sabe-se que pode haver desenvolvimento de tolerância à planta por ajustamento da microbiota gastrintestinal, assim como interferência de fatores relacionados com o seu ciclo, ou ainda podem existir organismos (p. ex. fungos) que tornam a planta tóxica em determinadas ocasiões. Neste surto, possivelmente, uma das condições que determinou a toxidez da planta foi a adubação do solo com fosfato de rocha, meses antes da ingestão da planta. De qualquer forma, o princípio tóxico relacionado com a nefrose tubular tóxica produzida por espécies do gênero Amaranthus continua desconhecido.

Embora não tenham sido realizadas avaliações bioquímicas nos animais desse estudo, as lesões foram atribuídas à uremia, decorrente da lesão renal. De fato, os sinais clínicos e as lesões encontradas são semelhantes às descritas por outros autores, que encontraram níveis elevados de uréia e creatinina e baixos de cálcio nos bovinos intoxicados espontaneamente por Amaranthus spp (Stuart et al. 1975, Armesto et al. 1989, Ferreira et al. 1991).

À necropsia, lesões de gastrenterite ulcerativa, semelhantes às descritas por Lemos et al. (1993) em bovinos intoxicados por $A$. spinosus não foram observadas nos ovinos desse surto; esse fato sugere que a amônia, nos casos de insuficiência renal em ovinos, não seja eliminada em grande quantidade pelo tubo digestivo.

Lesões hepáticas, caracterizadas principalmente por necrose de coagulação foram observadas na maioria dos animais deste estudo, podem ser esperadas em animais com toxemia ou choque (Kelly 1985). A ocorrência de tais lesões também é comum em casos de intoxicação por plantas nefrotóxicas (Jones \& Hunt 1983).

Pneumonia intersticial aguda, presente em alguns ovinos deste estudo, deve-se, provavelmente, à excreção de amônia pelas vias respiratórias. Já os processos de broncopneumonia exsudativa ocorreram por infecção secundária, enquanto as áreas de broncopneumonia necrotizante foram determinadas, ao que tudo indica, pela aspiração de conteúdo ruminal.

Pequenas hemorragias observadas em casos de intoxicação por Amaranthus spp, possivelmente devam-se a lesões no endotélio vascular associadas à uremia. Por outro lado, dados a extensão e o volume de sangue do hematoma presente no mesentério de um ovino deste estudo, pode ser que distúrbios da coagulação sangüínea também estejam implicados na gênese dos processos hemorrágicos desta lesão. Na intoxicação por $A$. spinosus em bovinos, lesões semelhantes foram descritas por Lemos et al. (1993).

No que se refere às alterações cardíacas, alguns aspectos merecem considerações especiais. Áreas de necrose coagulativa no coração de animais intoxicados espontaneamente por 
Amaranthus spp, não haviam sido descritas em nenhuma espécie animal. A única referência a este tipo de lesão encontra-se no estudo experimental com $A$. caudatus em suínos, realizado por Takken \& Connor (1985) na Austrália; porém, Osweiler et al. (1969) já haviam detectado alterações no eletrocardiograma de suínos intoxicados com $A$. retroflexus e relacionado o fato com a elevação sérica dos níveis de potássio. Não sabemos se tal se deve a uma desatenção com o exame histológico desse órgão, ou se esse tipo de lesão ocorre raramente. De qualquer forma, a patogenia parece evidente. Takken \& Connor (1985) propõe a hipercalemia secundária à lesão renal como determinante da lesão do miocárdio. A hipercalemia pode ser uma complicação séria da insuficiência renal em humanos, nos quais é uma das principais causas de astenia miocárdica e insuficiência cardíaca fatal que ocorre na uremia (Radostits et al. 2002).

O estudo histopatológico não revelou, de forma inconteste, nos fetos lesões determinadas diretamente pela planta. Provavelmente, o que ocorreu foi um estado toxêmico com conseqüiente aborto. $\mathrm{O}$ achado de corpúsculos de choque em vasos de alguns fetos reforçam esta hipótese.

Não se conhece tratamento para a forma nefrotóxica da intoxicação por Amaranthus spp em ovinos. Métodos profiláticos incluem a roçagem de áreas invadidas antes de se colocarem os animais nas pastagens, uma vez que a planta dessecada perde consideravelmente a toxidez (Osweiler et al. 1969, Ferreira et al. 1991). No entanto, tais medidas devem ser adotadas com certa cautela, uma vez que a intoxicação, por nós observada, ocorreu após a introdução dos ovinos em um piquete invadido por $A$. spinosus, que previamente havia sido roçado. Além de certificar-se de que o local foi bem roçado, o que não ocorreu neste caso, já que $A$. spinosus ainda apresentava-se com talos, deve-se tomar cuidado ao permitir que animais com fome tenham acesso a esses piquetes. Strom (1967) descreve um surto em ovinos, no qual os animais, após um período de privação alimentar devida ao transporte, se intoxicaram ao serem transferidos para um pasto repleto de Amaranthus spp. Em relação à toxidez, talvez o tempo decorrido entre a roçagem do pasto e a introdução dos ovinos, tenha sido curto o bastante para permitir que $A$. spinosus não perdesse por completo seu potencial de causar intoxicação.

Tentativas de reprodução da intoxicação com a planta em ovinos, não tiveram sucesso, provavelmente porque, nos experimentos, não se utilizou $A$. spinosus proveniente de áreas adubadas.

Agradecimentos.- Nossos agradecimentos ao Prof. Dr. David Driemeier, patologista da UFRGS, pela coloração hematoxilina fosfotungstica de Mallory, realizada em alguns cortes.

\section{REFERÊNCIAS}

Armesto R.R., Grande H.A., Baroni A.C., Baroni E.E. \& Boggio J. 1989. Intoxicación por Amaranthus quitensis em vaquillonas holando argentino. Vet. Argent. 6(60):692-700.

Brakenridge D.T. 1956. Nitrate poisoning caused by turnips and redroot. N.Z. Vet. J. 4:165-166.

Buck W.V., Preston D.S. \& Abel M. 1965. Common weeds as a cause of perirenal edema in swine. Iowa State Univ. Vet. 27:105-108.

Buck W.V., Preston K.S., Abel M. \& Marshall V.L. 1966. Perirenal edema in swine: a disease caused by common weeds. J. Am. Med. Vet. Assoc. 148:1525-1531.
Cho S.W. \& Lee C.S. 1984. Histopathological observations on natural disease and the experimental occurrence of perirenal oedema in pigs. Korean J. Vet. Res. 24(2):173-182. (Vet. Bull. 55(6), Abstr. 3791)

Clarke M., Harvey D.G. \& Humphreys D.J. 1981. Amaranthaceae. Veterinary Toxicology. 2nd ed. Baillieri Tindall, London. p.194-195.

Cursack H.A. \& Romano L.A. 1967. Posible intoxicatión sub-aguda com nitratos y nitritos. Gaceta Vet. 29:69-74.

Dodd, D.C. \& Coup M.R. 1957. Poisoning of cattle by certain nitrate containing plants. N.Z. Vet. J. 5:51-54.

Duckworth R.H. 1975. Poisoning of cattle by Amaranthus. N.Z. Vet. J. 23:154155.

Duffi S.J., Leon E.A., Gavier M.D., Vieira FJ.B., Corbellini C.N. \& Morra M. 1985. Intoxicación por Amaranthus quitensis (Yuyo colorado) en bovinos. Vet. Argent. 2:942-949.

Egyed M. \& Miller A. 1963. Nitrate poisining in cattle due to feeding on Amaranthus retroflexus. Refuah Veterinarith 20:167-169.

Ferreira J.L.M., Riet-Correa F., Schild A.L. \& Méndez M.C. 1991. Intoxicação por Amaranthus spp. (Amaranthaceae) em bovinos no Rio Grande do Sul. Pesq. Vet. Bras. 11(3/4):49-54.

González S.C. 1983. Nefrosis tubular tóxica en ovinos y caprinos asociada a la ingestión de plantas del gênero Amaranthus. Vet. Mexicana 14:247-251.

Jeppesen A.E. 1966. Bovine perirenal disease associated with pigweed. J. Am. Med. Vet. Assoc. 149:22.

Jones T.C. \& Hunt R.D. 1983. Veterinary Pathology. 5th ed. Lea \& Febiger, Philadelphia, p.901-1030.

Kelly W.G. 1985. The liver and biliary system, p.239-312. In: Jubb K.V.F. \& Kennedy P.C. (ed.) Pathology of Domestic Animals. Vol. 2. 3rd ed. Academic Press, Orlando.

Kommers G.D., Torres M.B., Dantas A.F. \& Barros C.S.L. 1996. Intoxicação por Amaranthus spp (Amaranthaceae) em suínos no Rio Grande do Sul. Pesq. Vet. Bras. 16(4):121-125

Larsen H.E., Aalund O. \& Nielson K. 1962. Perirenal edema in pigs. Nord. Vet. Med. 14:338-355.

Lemos R.A., Barros C.S.L., Salles M.S., Barros S.S. \& Peixoto P.V. 1993. Intoxicação espontânea por Amaranthus spinosus (Amaranthaceae) em bovinos. Pesq. Vet. Bras. 13(1/2):25-34.

Marshall V.L., Beck W.B. \& Bell G.L. 1967. Pigweed (Amaranthus retroflexus) an oxalate-containing plant. Am. J. Vet. Res. 28:888-889.

Mugerwa J.S. \& Starfford W. 1975. Effect of feeding oxalate-rich Amaranthus on ovine serum calcium and oxalate levels. S. Afr. For. J. 42:71-75.

Osweiler G.D., Buck W.B. \& Bicknell E.J. 1969. Production of perirenal edema in swine with Amaranthus retroflexus. Am. J. Vet. Res. 30:559-566.

Radostits O.M., Gay C.C., Blood D.C. \& Hinchcliff K.W. 2000. Veterinary Medicine. 9th ed. W.B. Saunders, London, p.479-500.

Rae C. A. \& Binnington B. D. 1995. Amaranthus retroflexus (redroot pigweed) poisoning in lambs. Can. Vet. J. 36(7):446.

Rivera M., Aquilo R., Lorenzo M., Ferro M. \& Villalon J. 1984. Reporte de intoxicación en bovinos jóvenes por el Amaranthus viridis (bledo blanco). Revta Cub. Cienc. Vet. 15:335-338.

Salles M.S., Barros C.S.L., Lemos R.A. \& Pilati C. 1991. Perirenal edema associated with Amaranthus spp. poisoning in Brazilian swine. Vet. Hum. Toxicol. 33(6):616-617.

Sanko R.E. 1975. Perirenal edema in swine caused by ingestion of Amaranthus retroflexus (pigweed). Vet. Med. Small Anim. Clin. 70:42-43.

Strom C.G. 1967. Lush plants can kill. Qd Agric. J. 93:498-499.

Stuart B.P., Nicholson S.S. \& Smith J.B. 1975. Perirenal edema and toxic nephrosis in cattle, associated with ingestion of pigweed. J. Am. Vet. Assoc. 167:949-950.

Takken A. \& Connor J.K. 1985. Some toxicological aspects of grain amaranth for pigs, p.170-177. In: Seawrigth A.A., Hegarty M.P., James L.F. \& Keeler R.F. 1984. (ed.) Plant Toxicology. Proc. Australia-USA Poisonous Plants Symposium, Queensland Poisonous Plant Committee, Brisbane, Australia, Yeerongpilly.

Tokarnia C.H., Döbereiner J. \& Peixoto P.V. 2000. Plantas Tóxicas do Brasil. Editora Helianthus, Rio de Janeiro. 320p. 